\title{
¿Buen gobierno corporativo en curso?
}

\author{
Renzo Alfredo Canalle Paz \\ Instituto Nacional de Defensa de la Competencia y de la Protección \\ de la Propiedad Intelectual, Lima, Perú
}

Recibido: 20/7/2018 / Aprobado: 1/2/2019

doi: 10.26439/iusetpraxis2018.n48-49.4498

\begin{abstract}
Resumen. En el presente artículo, se analiza la posibilidad, desde la norma concursal, de que la Junta de Acreedores pueda implementar el plan de lineamientos de buen gobierno corporativo, como mecanismo adicional a los establecidos en la Ley General del Sistema Concursal, para dotar de mayor valor a la concursada no solo en beneficio de los acreedores, sino también de terceros, en aras de conseguir la recuperación del crédito.
\end{abstract}

PALABRAS CLAVE: empresa / reestructuración patrimonial / Junta de Acreedores / plan de reestructuración / buen gobierno corporativo / lineamientos / valor

\section{Good corporate governance in progress?}

Авsтract. This article analyzes the possibility, from the bankruptcy law, that the creditors' committee could implement good corporate governance guidelines as an additional mechanism to those already established in the General Bankruptcy Law. Said guidelines aim at providing higher value to the insolvent, not only to benefit the creditors but also third parties in furtherance of credit recovery.

KEYWORDS: company / asset restructuring / creditors' committee / restructuring plan / good corporate governance / guidelines / value 


\section{INTRODUCCIÓN}

El objetivo de este artículo es hacer un aporte al derecho concursal, puntualmente, en los casos de empresas en reestructuración patrimonial, mediante una aproximación a los principios de BGC (en adelante, BGC). Así se intentará conciliar la materia del derecho, cuyo objeto es tratar la situación de crisis de una sociedad frente a sus acreedores, y la que se aplica a empresas que, por lo general, cotizan en el mercado y cuyos lineamientos proporcionan mayor valor a la sociedad.

Las empresas en reestructuración patrimonial son aquellas que, habiendo sido declaradas en concurso ante la autoridad administrativa (Indecopi), han ingresado a un procedimiento que les permitirá, sobre la base de un plan de reestructuración aprobado por la Junta, mantenerse en el mercado y continuar con las actividades productivas para pagar a los acreedores. Por su parte, los lineamientos de BGC suelen ser adoptados por las Juntas de Accionistas de sociedades que no han pasado por una crisis financiera, en el marco de un procedimiento concursal. Se trata de empresas que, teniendo una situación financiera eficiente, procuran alcanzar mayor valor en el mercado, pues al adoptar tales lineamientos se brinda al inversionista un marco de confianza y transparencia que redunda en beneficio de los accionistas.

Sin embargo, el solo hecho de que la concursada pase por un procedimiento de reestructuración patrimonial nos da una idea muy clara del propósito de la Junta de Acreedores. Al aprobar un plan de reestructuración, según la Ley General del Sistema Concursal (en lo sucesivo, la Ley), se activan los mecanismos necesarios para lograr una reestructuración exitosa, tales como cambiar el régimen laboral, ampliar el giro del negocio, incorporar capital de trabajo de nuevos inversionistas, vender activos prescindibles, entre otros. De esa manera, la adopción de los lineamientos de BGC sería, para la Junta de Acreedores, un mecanismo adicional a los establecidos en la Ley que permita dotar de mayor valor a la concursada, en beneficio de los acreedores que están expectantes por recuperar sus acreencias. En virtud de ello, este artículo se abocará a desarrollar respuestas a las siguientes preguntas:

- ¿La Junta de Acreedores está facultada a adoptar los lineamientos de BGC, como políticas dentro del plan de reestructuración patrimonial?

- ¿Los principios de BGC pueden dotar de mayor valor al patrimonio sometido a reestructuración patrimonial, en aras de conseguir 
más eficientemente el objetivo de la normativa concursal, que es la recuperación del crédito?

- ¿Es posible plantear lineamientos de BGC propios de la realidad concursal de sociedades en reestructuración patrimonial?

\section{LA REESTRUCTURACIÓN PATRIMONIAL DE EMPRESAS EN SITUACIÓN DE CONCURSO}

A continuación, se hará una referencia general a aspectos relevantes de la realidad concursal de una sociedad sometida a reestructuración patrimonial, tales como la Junta de Acreedores, el régimen de reestructuración y el plan de reestructuración.

\section{La Junta de Acreedores}

El sistema concursal peruano, a través de la Ley General del Sistema Concursal, se sustenta, a diferencia del antiguo sistema judicial de quiebra, en una corriente privatista que proporciona a los principales afectados por la crisis de una empresa, sometida a un procedimiento concursal tramitado ante Indecopi, la posibilidad de adoptar los mecanismos que les permitan recuperar sus acreencias. Así pues, son los acreedores los que tienen la carga de impulsar el concurso. En efecto, el artículo VII de la Ley General del Sistema Concursal precisa que los concursos se inician siempre de parte y que su impulso corresponde a los privados, siendo subsidiaria la intervención del Estado. Por otro lado, es pertinente indicar que el objetivo de la normativa concursal es la recuperación del crédito. Este aspecto ha sido recogido expresamente en el artículo I de la misma Ley, por lo que, en aplicación del principio de impulso privado antes mencionado, se busca que sean los propios acreedores los que decidan, en tal marco normativo concursal, cómo cobrar sus créditos.

En conjunción con el objeto de la norma concursal, esta ha establecido una finalidad muy clara, regulada en el artículo II del Título Preliminar, por la cual tal objetivo debe obtenerse mediante acuerdos que los acreedores deberán adoptar en Junta, en reemplazo de la Junta de Accionistas, cuyas funciones se suspenderán. De esta manera, la Junta de Acreedores es el mecanismo de negociación por excelencia en el marco concursal, toda vez que, en un solo ambiente, con bajos costos de transacción y con base en la autonomía privada, los acreedores tienen la posibilidad de 
lograr acuerdos relevantes sobre el destino de la empresa deudora, que los puedan llevar a maximizar el cobro de sus acreencias.

En la Resolución 055-97-TDC del 26 de febrero de 1997, el Tribunal de Defensa de la Competencia y de la Propiedad Intelectual señala que la Junta de Acreedores es el órgano deliberativo de la masa de acreedores. Se trata del mecanismo por el cual estos intervienen en el concurso, manifestando su voluntad a través de la adopción de acuerdos y supervisando la marcha de los procedimientos de reestructuración. A su vez, la Sala de Defensa de la Competencia del Tribunal de Indecopi afirma que el poder atribuido a la Junta de Acreedores resulta determinante para el desarrollo del proceso concursal, considerando que reemplaza a la Junta de Accionistas como órgano máximo de decisión en una empresa en crisis y asume el gobierno total de la misma. Por ello, está facultada no solo a decidir el destino de su patrimonio y su régimen de administración, sino también a controlar y supervisar cada etapa en la marcha del negocio (Resolución 0707-2006/TDC-INDECOPI, 2006).

\section{La reestructuración patrimonial}

La Ley General del Sistema Concursal define la reestructuración patrimonial como el destino acordado por la Junta de Acreedores, con una mayoría calificada, por el cual la empresa ingresa a un procedimiento que le permita continuar con sus actividades y giro del negocio, $\mathrm{y}$, por lo tanto, mantenerse en el mercado.

Ezcurra Rivero (2005) nos ilustra sobre las facultades de la Junta de optar por una reestructuración patrimonial. Indica que la Ley concede a los acreedores la posibilidad de evaluar y aprobar por mayoría la propuesta de reestructuración de pasivos que plantee el deudor, con el objetivo de brindarles la oportunidad de evaluar si el plan de pagos presentado maximizará el valor del negocio y, con ello, la recuperación de sus créditos (p. 255). Este es un destino muy relevante, pues para la recuperación de los créditos (objetivo de la Ley), con base en el impulso privado, los acreedores han debido hacer una evaluación financiera y de mercado de la empresa sometida a concurso, y haber estimado que, si la misma se mantiene en el giro, su valor - no necesariamente en términos contables, sino en términos financieros - es mayor que la suma de sus activos menos sus pasivos. Por tanto, una reestructuración patrimonial implica que los acreedores consideran que la empresa es capaz de generar flujos de caja futuros que le permitan, además de pagar los créditos 
concursales, cumplir con sus obligaciones con otros proveedores y mantenerse en el mercado.

La reestructuración patrimonial, a diferencia de la liquidación concursal, no solo por sus efectos concursales, sino también por sus efectos financieros, económicos y de presencia en el mercado, conlleva un intrínseco y responsable estudio de los acreedores, quienes, a partir de su autonomía privada, depositan su confianza en la sociedad concursada. Luego, al acordar la reestructuración, la Junta de Acreedores debe a su vez aprobar un plan de reestructuración patrimonial, que es el instrumento contractual y concursal que determina cómo se recuperarán las acreencias y la empresa proseguirá con sus actividades. En esta línea, la segunda instancia de la Resolución 0608-2005/TDC -INDECOPI concluye que si la Junta optara por la reestructuración del deudor, también tiene que aprobar un plan de reestructuración que establezca las condiciones en que cada acreedor podrá hacer efectiva la recuperación de sus créditos.

\section{El plan de reestructuración}

El artículo 66 de la Ley General del Sistema Concursal define el plan de reestructuración de la siguiente manera:

Artículo 66.- Contenido del plan de reestructuración

66.1 El plan de reestructuración es el negocio jurídico por el cual la Junta define los mecanismos para llevar a cabo la reestructuración económico-financiera del deudor, con la finalidad de extinguir las obligaciones comprendidas en el procedimiento y superar la crisis patrimonial que originó el inicio del mismo, en función de las particularidades y características propias del deudor en reestructuración. (Ley General del Sistema Concursal, 2002)

Como puede apreciarse, dicho instrumento es considerado como un negocio jurídico celebrado entre los acreedores, por lo que podemos deducir que tiene una evidente naturaleza contractual.

En efecto, no existe intervención alguna del Estado, representado por Indecopi, en la elaboración y aprobación del plan de reestructuración. En consecuencia, no es un acto administrativo, sino jurídico de índole contractual multilateral, por lo que obliga al deudor y a todos los acreedores. Indecopi se limita a verificar que se cumplan los requisitos de validez que la norma concursal exige, mas no la viabilidad ni pertinencia 
de los mecanismos que los acreedores acuerden poner en marcha. Su participación se restringe a verificar el cumplimiento de los requisitos de quorum y mayorías legales; sin embargo, ello no implica que participe en la formación de la voluntad de los acreedores al aprobar un instrumento concursal, razón por la cual este último es un negocio jurídico y no uno administrativo.

Por otro lado, la norma circunscribe el propósito del plan a extinguir las obligaciones comprendidas en el procedimiento y superar la crisis patrimonial. No obstante, consideramos que este instrumento no se limita a dicha finalidad. La propia norma en su artículo 66.2 señala que en el plan se podrá detallar (i) la información financiera de la empresa, (ii) las acciones que la administración pretende adoptar, (iii) las propuestas de financiamiento de la inversión requerida para la continuación del giro de la empresa, (iv) la política laboral, (v) el régimen de intereses, (vi) el flujo efectivo proyectado en el tiempo, entre otros.

Así las cosas, conforme a la norma concursal, el plan puede contener la información contable, las acciones que se propone ejecutar la administración, las propuestas para el financiamiento de la inversión requerida para la continuación de la actividad del deudor, la política laboral que se va a adoptar, el régimen de intereses, así como un estado de flujos de caja proyectado en el tiempo previsto para el pago de la totalidad de las obligaciones comprendidas en el procedimiento. Lo antes referido nos conduce a afirmar que, si bien el plan tiene un propósito definido en la norma, es decir, la extinción de las obligaciones en concordancia con el objetivo del sistema concursal, en dicho contrato la Junta puede adoptar cualquier otra medida o acción que coadyuve a la obtención del citado objeto. Por tanto, el plan no solo será un mero cronograma de pagos.

De este modo, los acreedores tienen la posibilidad de establecer mecanismos para cumplir con el objetivo del plan, que es reestructurar financieramente al deudor para que, manteniéndose en el mercado con su giro, se puedan pagar los créditos reconocidos. En ese sentido, nos podemos aproximar a la idea preliminar de que la Junta tiene plena facultad para adoptar en el plan cualquier medida o acción -que evidentemente no linde con lo ilegal ni transgreda la normativa concursal - para contribuir a la consecución del objeto del contrato. Por ejemplo, podría cambiar el giro del deudor, vender la marca comercial y cambiarla por otra, reorganizar estructuralmente la empresa, aprobar 
reformas societarias, acordar una fusión societaria o adquirir por esa vía otra empresa, entre otras posibilidades que el ordenamiento jurídico contemple y que les sirva para lograr el objetivo de maximizar el cobro de sus créditos.

En consecuencia, a fin de establecer una base en el análisis que se efectuará en este artículo, entre las opciones que pueden ser acordadas por la Junta en el plan estaría aquella que permita a la empresa aplicar los lineamientos de BGC, con el objeto de que, además de prever acciones para el pago de las obligaciones establecidas en la norma concursal a favor de los acreedores, se implementen mecanismos adicionales para garantizar la transparencia y la eficiencia en la empresa, en aras de dotarla de mayor valor en el mercado y atraer las inversiones.

De esa manera, se cuenta con los elementos para concluir que no existe impedimento legal, al menos desde el punto de vista concursal, para que la Junta de Acreedores pueda adoptar los lineamientos de BGC, que se incluirán como políticas dentro del plan de reestructuración. Estos lineamientos dotan de mayor valor al patrimonio sometido a reestructuración patrimonial para conseguir más eficientemente el objetivo de la normativa concursal, que es la recuperación del crédito.

\section{LOS PRINCIPIOS DE BGC APLICABLES A UNA REESTRUCTURACIÓN PATRIMONIAL}

A continuación, se analiza la normativa que recoge los lineamientos de BGC, así como la doctrina sobre tal materia, con la finalidad de determinar si con ellos es posible dotar a la empresa en reestructuración patrimonial de mayor valor y conseguir el objetivo de la norma concursal, que es la recuperación del crédito. Los lineamientos de BGC tienen como objetivo desarrollar mecanismos por los cuales las sociedades son dirigidas, en aras de brindar transparencia y control a la actividad empresarial.

Para empezar, podemos esbozar la definición de gobierno corporativo (GC). Benavides (2015) indica que el concepto de GC está íntimamente ligado al de la firma, y que esta última es la unidad conceptual sobre la cual actúa el GC. Este debe propender a la eficiencia de la firma en lo que respecta a las relaciones entre sus administradores, propietarios y, más recientemente, a la sociedad en general (p. 1). De lo anterior, se puede colegir que el concepto de gobierno corporativo comprende el conjunto 
de estrategias que permiten lograr un mejor ámbito jurídico, económico y social de la empresa, pues procura abarcar las relaciones entre los partícipes de su realidad, tales como los accionistas, los directores, gerentes, proveedores, acreedores, trabajadores y la sociedad.

Esta idea llevaría a afirmar que la aplicación de estrategias por parte de la Junta de Acreedores a la realidad concursal puede conducir a un mejor ámbito jurídico, económico y social de la empresa en reestructuración patrimonial. Esto se debe a que el propósito es generar lineamientos que, a la par con las disposiciones de la Ley General del Sistema Concursal, generen mayores y eficientes relaciones con sus acreedores, Indecopi, la administración o entidad administradora elegida (que incluye a directores y gerentes), los clientes y trabajadores de la concursada y, por cierto, sus potenciales inversionistas.

Por otro lado, Benavides (2015), analizando los alcances del gobierno corporativo, precisa que el gobierno de la corporación se define por agregar valor y moldear los diferentes mecanismos internos diseñados para ejercer el control y monitoreo sobre los encargados de manejar la firma (p. 1). En ese sentido, el gobierno corporativo busca establecer los medios que no solo permitan a la empresa lograr sus metas, sino también poner en funcionamiento mecanismos para el respectivo seguimiento, supervisión y medición. A partir de esa premisa, el BGC procura poner en marcha incentivos dentro de la estructura societaria de la empresa a fin de lograr eficiencia en los ámbitos antes mencionados, así como en la consecución de los objetivos sociales en beneficio de los inversionistas. El concepto de agregar valor mediante la eficiencia que dota el GC es el fundamento de la propuesta de este artículo, pues sus lineamientos servirían para dar mayor valor a la concursada, con lo cual nos acercaremos más al objetivo de la norma concursal, que es la recuperación del crédito.

Para Barona Zuluaga (2015), la importancia de las buenas prácticas de GC es que el buen gobierno se asocia, en gran medida, a la protección de los proveedores de fondos a las empresas y se considera como uno de los elementos importantes del desarrollo financiero. Añade el autor que los mercados financieros más desarrollados permiten a las empresas tener un acceso más amplio a los recursos financieros a un costo menor, lo cual redunda en mayores tasas de crecimiento y generación del empleo (p. 1). Este análisis nos lleva a entender el real valor del GC, pues se constituye como un factor fundamental para brindar a la 
empresa mayor competitividad en el mercado, lo que se traducirá en generar confianza en los inversionistas. De esa manera, si la confianza de los inversionistas es positiva, esto ayudará a mejorar la economía de mercado en el país, de lo cual se deduce que el uso eficiente de recursos generará la reducción de los costos de acceso de capital.

Aplicada esta idea al ámbito concursal, se puede encontrar un motivo más para comprender el real aporte financiero que las buenas prácticas de GC pueden traer a una empresa en reestructuración patrimonial. En efecto, si nos enfocamos en los inversionistas interesados en una empresa que se está reestructurando bajo el sistema concursal, podemos afirmar que una verificación de la adopción y ejecución seria de los lineamientos de BGC por parte de la Junta de Acreedores, ineludiblemente, le dará mayores incentivos para invertir en la concursada. Esto será muy valioso para los acreedores, pues la inversión traerá mayor valor a la sociedad y, por tanto, contribuirá a la recuperación de sus créditos, alineándonos con el objetivo de la norma concursal. De lo anterior, se puede deducir una aproximación más concreta a la definición, alcances y relevancia del BGC, en su aplicación a la realidad de una sociedad concursada en reestructuración patrimonial. Ante ello, se concluye que es perfectamente viable y útil para los acreedores y sana para posibles inversionistas la incorporación de los lineamientos o principios de BGC en el ámbito concursal.

La Organización para la Cooperación y el Desarrollo Económico (OCDE), en el documento Principios de gobierno corporativo de la OCDE (2004), ha desarrollado lineamientos para ayudar a los Gobiernos de los países miembros o no de la OCDE en la tarea de evaluar y perfeccionar los marcos legales, institucionales y reglamentarios aplicables al gobierno corporativo en sus respectivos países, así como ofrecer orientación y sugerencias a las bolsas de valores, los inversores, las sociedades y demás partes que intervienen en el proceso de desarrollo de un modelo de BGC. Asimismo, en dicho documento, hace una declaración estrechamente relacionada con la finalidad de la norma concursal establecida en el artículo II del Título Preliminar de la Ley General del Sistema Concursal, el cual busca que, con base en la negociación de los acreedores y el deudor, los acuerdos de reestructuración se adopten bajo reducidos costos de transacción. En efecto, la OCDE indica que la existencia de un sistema eficaz de gobierno corporativo dentro de una sociedad determinada y dentro del conjunto de la economía contribuye 
a generar el grado de confianza necesario, procurando que el coste de capital se reduzca y se incite a las empresas a utilizar sus recursos de forma más eficiente a fin de potenciar su crecimiento.

Del mismo modo, la OCDE señala que el sistema de gobierno corporativo aborda las relaciones que se presentan en la realidad de la empresa, tales como los directores y gerentes, los accionistas, los acreedores y los empleados. En cuanto a los acreedores, refiere que en el marco de un proceso concursal revertirá en muchísima preponderancia. A su vez, indica que los acreedores desempeñan un papel destacado en diversos sistemas de gobierno, y pueden servir como agentes supervisores de los resultados de la sociedad. Ello, en el concurso, se presenta y configura plenamente, con la evidente distinción de una empresa no concursada, respecto a la cual los acreedores no tienen el poder de determinar el destino de la sociedad ni la composición de sus órganos de administración y de dirección.

Se han identificado los siguientes principios de gobierno corporativo de la OCDE, que se analizarán a la luz de la normativa concursal:

a. Garantizar la base de un marco eficaz para el gobierno corporativo

b. Los derechos de los accionistas y funciones clave en el ámbito de la propiedad

c. Tratamiento equitativo de los accionistas

d. El papel de las partes interesadas en el gobierno corporativo

El primer principio indica lo siguiente: “El marco para el gobierno corporativo deberá promover la transparencia y eficacia de los mercados, ser coherente con el régimen legal y articular de forma clara el reparto de responsabilidades entre las distintas autoridades supervisoras, reguladoras y ejecutoras" (OCDE, 2004, p. 17).

Si bien este principio es una recomendación a los Gobiernos para establecer marcos favorables al gobierno corporativo, podemos decir, desde el punto de vista concursal, para el caso concreto de una empresa en reestructuración patrimonial, que la Ley General del Sistema Concursal deja a los acreedores en libertad de incluir en el plan de reestructuración cualquier disposición o lineamiento que no vulnere la normativa. Así pues, consideramos que el marco particular para la implementación de lineamientos de gobierno corporativo debería estar 
establecido en el plan de reestructuración patrimonial. Este, como se ha desarrollado en el primer capítulo, es el instrumento que regirá la sociedad en reestructuración durante el tiempo que el procedimiento concursal esté en trámite. En este sentido, el plan tiene que determinar las condiciones para la transparencia de la información sobre las acciones de la administración, a fin de que los acreedores estén lo suficientemente informados del curso de la reestructuración.

El segundo principio se desarrolla de la siguiente manera: "El marco para el gobierno corporativo deberá amparar y facilitar el ejercicio de los derechos de los accionistas" (OCDE, 2004, p. 18).

Ciertamente, en la vida de una empresa en reestructuración patrimonial, los accionistas tienen una participación restringida en el ámbito procesal, en la medida en que la Junta de Accionistas está suspendida de sus funciones y es reemplazada por la Junta de Acreedores. En ese sentido, al ser los acreedores quienes tienen el poder de decidir el destino de la firma concursada, en la práctica son los verdaderos propietarios hasta que se extinga la Junta por el pago total de las acreencias. El marco legal de la norma concursal contiene varias disposiciones que regulan los derechos de los acreedores al voto en Juntas, a la fiscalización de la administración y al cobro de sus créditos.

Así, la Ley General del Sistema Concursal establece disposiciones tales como (i) el artículo 52, que consagra el derecho de información de los acreedores en Junta; (ii) el artículo 50.4, que regula el derecho a voz y voto en las Juntas, la elección de la administración, su régimen y las autoridades de la Junta; (iii) el artículo 69, relativo a la facultad del acreedor reconocido de cobrar sus acreencias preferentemente; (iv) el artículo 118, que desarrolla el derecho de impugnación de acuerdos a través del cual los acreedores minoritarios pueden denunciar abuso de derecho o vulneración de la Ley; (v) el artículo 122.3, que obliga a la entidad administradora a proporcionar información trimestral de cómo se viene ejecutando el plan de reestructuración; (vi) el artículo 67, que faculta a los acreedores a denunciar el incumplimiento del plan de reestructuración; y (vii) el artículo 114, que faculta a los acreedores a vender sus créditos.

A pesar de lo anterior, se considera que en el plan de reestructuración pueden establecerse, en paralelo con las disposiciones legales antes citadas, lineamientos y mecanismos sencillos y a bajo costo, que permitan coadyuvar a que las facultades de los acreedores sean más eficientes y 
transparentemente ejercidas, y a que cuenten con la información necesaria para la toma de decisiones dentro del concurso.

¿Qué derechos de los acreedores podrían consagrarse en un plan de reestructuración? Barona Zuluaga (2015), al analizar el segundo principio de la OCDE, refiere que los derechos básicos de los accionistas son los siguientes: (i) estipular los métodos de registro de la propiedad, (ii) traspasar o transferir acciones, (iii) recabar información relevante sobre la sociedad de manera periódica, (iv) participar y votar en las juntas generales de accionistas, (v) designar a los miembros del Consejo y (vi) participar en los beneficios de la sociedad (p. 2). Trasladando estos derechos al ámbito concursal, se puede afirmar que en el plan de reestructuración podrían establecerse mejores mecanismos de protección a los acreedores que los que la propia norma concursal estipula, y los derechos indicados por Barona Zuluaga (2015) perfectamente pueden servir para tal objetivo. Para poner un ejemplo, en el plan podrían implementarse mecanismos sencillos y menos costosos para que los acreedores se informen de la marcha de la reestructuración, usando medios electrónicos o páginas web.

Finalmente, es importante anotar que, en la vida del procedimiento de reestructuración patrimonial, los acreedores pueden acudir a la Comisión de Procedimientos Concursales de Indecopi que esté a cargo del expediente y denunciar cualquier irregularidad o fraude que pudiera ser pasible de sanción en el marco de la Ley General del Sistema Concursal. Este es un factor clave, pues la entidad estatal siempre puede servir no solo de puente para que la administración de la empresa concursada brinde la información, sino también como ente fiscalizador y sancionador de conductas que vulneren los derechos de los acreedores.

El tercer principio se desarrolla de la siguiente manera: "El marco para el gobierno corporativo deberá garantizar un trato equitativo a todos los accionistas, incluidos los minoritarios y los extranjeros. Todos los accionistas deben tener la oportunidad de realizar un recurso efectivo en caso de violación de sus derechos" (OCDE, 2004, p. 20).

Como se mencionó líneas arriba, la norma concursal contiene disposiciones expresas relativas a los derechos de los acreedores a voz, voto, información y fiscalización en el procedimiento de reestructuración patrimonial. Sin embargo, de manera explícita no encontramos una disposición - que estimamos que debiera haberse incluido en el Título Preliminar de la Ley - que consagre el tercer principio de la OCDE a 
favor del trato igualitario y equitativo de los acreedores. Si bien en la realidad concursal se puede tener como acreedores desde trabajadores (origen laboral), pasando por bancos y proveedores (origen comercial), hasta entidades estatales, tributarias y previsionales (origen tributario y previsional), la aplicación del citado principio nos llevaría a colegir que cualquiera de ellos, independientemente de la cuantía de sus créditos reconocidos - por ejemplo, un trabajador-, pueda, por el solo hecho de haber sido reconocido como acreedor, ejercer sus derechos y ser tratado por la administración de la empresa de la misma manera que uno mayoritario o entidad que maneja la Junta.

Barona Zuluaga (2015) examina el principio del trato equitativo de la OCDE y da mayores luces de sus alcances. Señala que este puede violarse en (i) el proceso de votación de las asambleas de los accionistas, (ii) el uso de información privilegiada por parte de los administradores y (iii) los conflictos de intereses en transacciones que puedan realizar los directivos (p. 3). Si bien la norma concursal reglamenta la participación de los acreedores en la Junta, garantizando sus derechos al voto, carece de disposiciones relativas al uso de la información privilegiada y a los conflictos de intereses referidos por el citado autor.

En tal sentido, como se indicó anteriormente al destacar el hecho de que la Ley General del Sistema Concursal no contiene una proclamación del principio del trato equitativo de la OCDE, sería muy saludable, al margen de que la norma concursal pudiera ser mejorada, que en un plan de reestructuración patrimonial no solo se proclame el trato equitativo e igualitario, sino que se implanten mecanismos que lo garanticen, particularmente en torno al uso de la información privilegiada y a los conflictos de intereses.

El cuarto principio OCDE se desarrolla de la siguiente manera:

El marco para el gobierno corporativo deberá reconocer los derechos de las partes interesadas establecidos por ley o a través de acuerdos mutuos, y fomentar la cooperación activa entre sociedades y las partes interesadas con vistas a la creación de riqueza y empleo, y a facilitar la sostenibilidad de empresas sanas desde el punto de vista financiero. (OCDE, 2004, p. 21)

$\mathrm{Al}$ respecto, Barona Zuluaga (2015) explica que con este principio la empresa tiene sus propios intereses y que, al velar por los de los grupos de interés social, se promueven y fomentan los propios intereses de la empresa. Añade que, como grupos de interés social, se considera 
explícitamente a los inversionistas, los empleados, los acreedores y los proveedores (p. 4).

Sobre el particular, en el marco de un procedimiento de reestructuración patrimonial, se puede afirmar que las partes más interesadas en la superación de la sociedad de la situación de concurso, por excelencia, son los acreedores reconocidos por la autoridad concursal, pues la propia Ley General del Sistema Concursal está orientada en su objetivo a la satisfacción del interés perseguido mediante la recuperación del crédito. Al hablar de los acreedores, como ya se ha expuesto, se incluye todo el espectro de deudas que mantiene la empresa y cuyos titulares pueden ser acreedores laborales miembros de sindicatos de trabajadores, entidades administradoras de fondos de pensiones, bancos, entidades tributarias, proveedores y ministerios del Estado. Por tanto, son estos acreedores las partes más relevantes que cuentan con la legitimidad activa y el poder de decisión en el procedimiento concursal.

No obstante, a la luz de lo planteado por Barona Zuluaga (2015), se puede esbozar la existencia de otras partes interesadas en el procedimiento de reestructuración, que tienen legítimas expectativas en su resultado y éxito. Una de ellas son los propios accionistas, quienes, según se ha visto, si bien carecen de derechos políticos y económicos en el concurso, creemos que sí tienen legitimidad para pedir información a la administración designada por los acreedores en Junta. La Ley no menciona esa facultad; es más, la norma, en su artículo 114, solo dice que la legitimidad de formular escritos corresponde a los acreedores reconocidos, aun cuando, en la práctica, en el marco de ciertos procedimientos, algunos accionistas de concursadas en reestructuración han plasmado sus pretensiones.

A pesar de ello, se prevé que los accionistas puedan formular denuncias de cualquier irregularidad que pueda afectar al patrimonio concursado y, con ello, a la sociedad que en algún momento retornará a sus manos. Estas facultades a favor de los accionistas pueden estar expresamente establecidas en el plan de reestructuración como principios de gobierno corporativo de la sociedad concursada, a fin de alinearse con el cuarto principio de la OCDE.

Por otro lado, los inversionistas, desde la perspectiva del autor, también son un grupo relevante de interés, pues pudieran ver a la empresa en reestructuración como una real oportunidad de negocios y, ante ello, decidan intervenir comprando las acreencias reconocidas por 
Indecopi. De esa manera, pueden ingresar a manejar la Junta de Acreedores y tomar decisiones en la administración de la firma.

La norma concursal tampoco contiene disposición alguna al respecto. Empero, en su defecto, el plan de reestructuración puede admitir lineamientos básicos que permitan a estos inversionistas recabar información de toda índole de la empresa, e incluso facilitar la realización de un $d u e$ diligence. Tales inversionistas pueden ejercer el derecho de comprar las acreencias mediante el procedimiento regulado en el artículo 114 de la Ley, que concierne al cambio de titularidad de créditos, en beneficio de los acreedores con la recuperación más rápida de sus acreencias. Así, adquieren participación relevante en la toma de decisiones en la Junta.

Otro grupo de interés son los trabajadores de la sociedad en marcha. Si bien muchos de ellos pudieran haber sido reconocidos como acreedores por devengos laborales impagos, al mantenerse la empresa en funcionamiento, necesitará contar con una fuerza laboral que le permita continuar en el mercado. Por lo tanto, los empleados de la empresa en reestructuración patrimonial deben ser considerados como un grupo de interés en el concurso.

Finalmente, los proveedores de la concursada en reestructuración también son un grupo de interés de la firma, porque ellos la dotarán de la materia prima, servicios e insumos, según su objeto social y rubro, para continuar con la actividad productiva.

Por lo antes expuesto, en aplicación del cuarto principio de la OCDE, se concluye que resulta de elevada trascendencia que el plan de reestructuración considere, en defecto de la norma concursal, lineamientos de gobierno corporativo a favor de los accionistas, los inversionistas, los empleados y los proveedores como partes interesadas, y hacer como propios dichos intereses en beneficio de los acreedores y la sociedad. De esa forma, desde el ámbito concursal, se abarcaría el abanico completo de grupos de interés sobre una empresa en reestructuración patrimonial.

\section{LOS LINEAMIENTOS CONCURSALES DE BGC}

\section{El mecanismo de inclusión de principios de BGC al concurso}

La normativa concursal, si bien está diseñada para afrontar crisis empresariales, contiene disposiciones específicas cuyo enfoque se orienta al tratamiento de realidades de sociedades, lo que facilita la 
aplicación de los lineamientos de BGC. Asimismo, como ya se ha planteado, a la luz de los principios de la OCDE, es importante que el plan de reestructuración prevea, en defecto de la norma concursal, lineamientos de gobierno corporativo a favor de todos los grupos de interés. En este punto, es relevante hacer referencia al tema relativo al mecanismo de incorporación de lineamientos al procedimiento de reestructuración patrimonial, conforme a la normativa concursal.

Se ha hecho referencia a que el plan de reestructuración es el mecanismo por excelencia por el cual los acreedores acuerdan las medidas de cualquier índole que se van a adoptar en la concursada cuyo destino ha sido la reestructuración patrimonial. Siempre, con la premisa de que dicho negocio jurídico es un contrato oponible a todos los acreedores y a la sociedad en concurso, en el cual se viabilizará la reestructuración de la concursada. Entre tales medidas, a fin de dar transparencia y predictibilidad al actuar de la sociedad en reestructuración y, por ende, mayor valor en el mercado ante los inversionistas y acreedores, se estima pertinente la aprobación de los lineamientos de gobierno corporativo por la Junta de Acreedores. En ese sentido, nuestra posición es que los lineamientos de BGC deben ser aprobados por la Junta e incluidos en el plan de reestructuración con el objeto de poder dotar al procedimiento concursal de predictibilidad y seguridad jurídica, pues mediante dicho instrumento concursal se materializa un contrato que es oponible a todos los acreedores, al haber sido aprobado por mayoría calificada exigida por la normativa concursal.

Independientemente de las conclusiones anteriores, que van en el sentido de que la adopción de lineamientos de BGC en la sociedad en reestructuración patrimonial será beneficiosa para los acreedores, al alinearse con el objetivo de la norma concursal, la posición indicada en el párrafo precedente podría ser cuestionada bajo la premisa de que la Ley General del Sistema Concursal no prevé de manera expresa que los lineamientos de BGC deban ser aprobados en Junta de Acreedores por mayoría calificada, que es la requerida para aprobar o modificar el plan de reestructuración. De acuerdo con este argumento, los lineamientos de BGC podrían ser aprobados por la Junta con mayorías simples sin que estén incluidos en un plan de reestructuración, sino en un documento paralelo.

Es cierto que la norma concursal, cuando menciona la necesidad de mayorías calificadas para la aprobación de acuerdos por parte de la Junta de Acreedores, solo hace referencia a la aprobación del destino de 
la empresa y del instrumento concursal. Sin embargo, nuestra posición de que los lineamientos de gobierno corporativo deben estar implementados y contenidos en el plan de reestructuración se sustenta, asimismo, en lo establecido en la propia Ley General del Sistema Concursal, cuyo artículo 66.1 estipula que dicho instrumento es el negocio jurídico por el cual la Junta de Acreedores define los mecanismos para llevar a cabo la reestructuración económico-financiera del deudor, con la finalidad de extinguir las obligaciones comprendidas en el procedimiento y superar la crisis patrimonial que la originó, en función de las particularidades y características propias del concursado. Esta sola referencia a la definición legal del plan de reestructuración lleva a afirmar que la aplicación de los lineamientos de BGC está dentro de los mecanismos para llevar a cabo una mejor reestructuración de la deudora.

Por otro lado, el artículo 66.2 de la norma concursal indica, entre otros aspectos, que el plan de reestructuración podrá detallar las acciones que se propone ejecutar la administración. Resulta muy evidente que los lineamientos de BGC están dentro de las acciones que la administración de la sociedad va a realizar para lograr una eficiente reestructuración de la empresa en cuestión.

En virtud de lo desarrollado, sin que este sea un tema cerrado y posiblemente discutido, en nuestra opinión, es en el plan de reestructuración donde deben incluirse los lineamientos de BGC de la sociedad en concurso.

\section{Los beneficios de la aplicación de los lineamientos de gobierno corporativo en empresas en crisis}

En este artículo, se ha mostrado que la implementación en la empresa concursada de los lineamientos de BGC dotaría de mayor valor a la sociedad en proceso dereestructuración patrimonial. A fin de complementar este análisis, abordaremos, a continuación, la opinión de entendidos en materia de GC, cuyos trabajos se orientan a examinar los beneficios de toda índole de aplicar tales lineamientos en empresas en crisis.

Díaz Ortega (2015), en el marco del curso de gobierno corporativo dictado en la Universidad ESAN, a cuyos materiales se ha tenido acceso, refiere que la lógica del análisis de esta materia radica en el enfoque de identificación de riesgos que limiten la creación de valor a través de las prácticas de GC. Así, menciona que la aplicación de lineamientos de gobierno corporativo en los ámbitos de (i) derecho de los accionistas, 
(ii) tratamiento equitativo a los accionistas, (iii) función de los grupos de interés, (iv) comunicación y transparencia informativa, y (v) responsabilidades del directorio y la gerencia, conduce a que las compañías sean mejor administradas y se alcancen objetivos relevantes que otorgarán competitividad a la empresa, tales como (a) una sociedad con menos riesgo, (b) un mejor costo de financiamiento y mayor acceso al capital, (c) la garantía de sostenibilidad de la empresa, (d) más oportunidades de negocio y (d) la consecución de mejores resultados operativos.

Como complemento a este análisis, Díaz Ortega (2015) se enfoca en los efectos de la aplicación de GC según los frentes de la sociedad, sea el interno o el externo. En el primero, concluye que los frutos del BGC son mayor eficacia, más incentivos al cumplimiento de metas, estímulo al desempeño y al liderazgo, optimización de la administración de riesgos y el clima interno, y estabilización de resultados. En el frente externo, refiere que se logra una mayor atracción para los negocios, pues se incrementa el acceso al mercado de capitales y se amplía el mercado de productos. A su vez, se mejora la reputación, la transparencia y la responsabilidad social.

De acuerdo con Díaz Ortega (2015), se pueden sacar evidentes y valiosas conclusiones de cómo podría beneficiar la aplicación de los lineamientos de BGC a una empresa en reestructuración patrimonial, pues la posibilidad de que la concursada tenga una mejor administración, menor riesgo, mejoras operativas y acceso al capital hará que los grupos de interés concursales - esto es, la Junta de Acreedores, los trabajadores, los proveedores y los inversionistas - vean a la deudora con mayor valor $\mathrm{y}$, en consecuencia, con mayor probabilidad de lograr el pago de las acreencias, que es el objetivo de la Ley General del Sistema Concursal. Ello, sumado a que la empresa sea pasible de recibir inversiones y más capital de trabajo, otorgará a la reestructuración patrimonial de mejores oportunidades de éxito.

Es pertinente señalar, con Díaz Ortega (2015), un aspecto que tiene relación directa con la realidad de una empresa en reestructuración patrimonial. El BGC sirve tanto en épocas de prosperidad como en tiempos de recesión económica. Así, cuando la economía y el mercado crecen, sus resultados positivos tangibles son evidentes; sin embargo, sus lineamientos ayudan también a las empresas a capear con mayor equilibrio las graves consecuencias de una crisis económica, lo que ha sido comprobado con los resultados de las conocidas crisis financieras 
globales. Este hecho redunda aún más en la idea de que los lineamientos de BGC coadyuvarían al objetivo de la norma concursal, pues sus efectos y beneficios también serán de utilidad para dar mayor valor a la empresa concursada. Esta, como lo hemos expuesto en el primer capítulo, precisamente, ingresa al sistema concursal por una situación de crisis financiera que la condujo a dejar de pagar a sus acreedores.

La Corporación Andina de Fomento (2010) precisa conclusiones afines a las de Díaz Ortega (2015). En efecto, esta entidad señala:

Cuando una empresa denota un alto estándar de GC, es percibida como una empresa más confiable, y como tal accede a mejores condiciones en los mercados en los que se desenvuelve. Asimismo, concluye que una mejor conducción del GC por sí mismo implica que la empresa sea más sólida y competitiva. Ineludiblemente, estos son efectos positivos para una empresa sometida a un procedimiento de reestructuración patrimonial. (pp. 6-9)

Morales Acosta (2007), cuando analizó el panorama del GC en el Perú, afirmó:

La aplicación de principios de BGC es un elemento clave para aumentar la eficacia económica y potenciar el crecimiento de la empresa, así como para fomentar la confianza de los inversionistas, dado que abarca toda una serie de relaciones entre el cuerpo directivo de una empresa, sus accionistas y otras partes interesadas. (p. 380)

En suma, las referencias a la utilidad, beneficios y efectos positivos de la aplicación de los lineamientos de BGC para una sociedad nos llevan a afirmar, una vez más, que su empleo en la realidad de una concursada en reestructuración patrimonial generará valor a la sociedad, en beneficio de la Junta de Acreedores y los demás grupos de interés, en perfecta armonía con el objetivo de la Ley General del Sistema Concursal.

\section{Las bases para elaborar lineamientos concursales de BGC}

Tomando como premisa que los lineamientos concursales de BGC deben ser adoptados por las Juntas de Acreedores, que han de evaluar libremente la posibilidad de aprobarlos y, con ello, dotar de mayor transparencia y valor a la empresa en el mercado, creemos necesario considerar las siguientes bases:

1. Lineamiento relativo a la transparencia y acceso a la información. Resulta de gran importancia para un eficiente procedimiento de 
reestructuración patrimonial, pues dotará a los acreedores y demás grupos de interés de mecanismos que permitan conocer de manera clara de qué manera se viene cumpliendo el plan de reestructuración patrimonial.

2. Lineamiento concerniente al ejercicio del derecho de voto de los acreedores en Junta. Otorga mecanismos adicionales a los establecidos en la Ley General del Sistema Concursal para viabilizar el mejor ejercicio de este derecho, lo que ineludiblemente redundará en beneficio de la reestructuración patrimonial.

3. Lineamiento referido al trato igualitario de los acreedores. Garantizar que estos, independientemente de su origen y participación porcentual en la Junta, puedan ser tratados de manera similar al resto de acreedores en sus pretensiones de acceder a información del concurso.

4. Lineamiento orientado a que se establezcan mecanismos que permitan a los inversionistas, trabajadores y proveedores acceder a información y participar en el proceso de una empresa que aún se mantiene funcionando en el mercado y generando riqueza.

5. Lineamiento orientado a que se cumplan las mejores condiciones para el desarrollo de la Junta de Acreedores, a fin de que los acreedores tengan mayor facilidad para asistir a la reunión y evaluar los temas de agenda, $\mathrm{y}$, en consecuencia, ejercer mejor su derecho al voto.

6. Lineamiento que determine y regule aspectos que la administración de la sociedad en reestructuración, liderada por el directorio, pueda implementar para generar transparencia, independencia y eficiencia en el uso y destino de la situación económica de los recursos y flujos de la sociedad.

\section{Conclusiones}

La Junta de Acreedores puede adoptar lineamientos de BGC, que serán incluidos como políticas dentro del plan de reestructuración. Estos dotarán al patrimonio sometido a reestructuración patrimonial de mayor valor, en aras de conseguir más eficientemente el objetivo de la normativa concursal, que es la recuperación del crédito. 
La reestructuración patrimonial es uno de los mecanismos adoptados por la Junta de Acreedores, bajo la premisa de que los acreedores consideran que la empresa es capaz de generar flujos de caja futuros que le permitan, además de pagar los créditos concursales, mantenerse en el mercado.

En tal sentido, es posible elaborar lineamientos concursales de BGC que serán aplicados a una realidad concursal de empresas en reestructuración patrimonial. No existe impedimento legal, al menos desde el punto de vista concursal, para que la Junta de Acreedores pueda adoptar estos principios. El mecanismo idóneo para la inclusión de los lineamientos de BGC a la reestructuración patrimonial es que la Junta los incorpore en el plan de reestructuración patrimonial, pues dicho instrumento concursal es el que regirá el procedimiento y resulta oponible a todas las partes.

La aplicación de los lineamientos de BGC en las sociedades, sobre todo en aquellas que estén pasando por crisis empresariales, las dota de mayor valor, pues su valor se incrementa al alcanzar mayor transparencia, competitividad, menor riesgo y abaratamiento del acceso al capital. Tal premisa se alinea con el objetivo de la Ley General del Sistema Concursal.

Los lineamientos concursales de BGC deben versar, primordialmente, sobre (i) la transparencia y acceso a la información del proceso de reestructuración, (ii) el ejercicio del derecho de voto de los acreedores en Junta, (iii) el trato igualitario de los acreedores, (iv) los grupos de interés en la reestructuración patrimonial y (v) el directorio y las medidas de administración de la sociedad.

\section{REFERENCIAS}

Baird, D. G. (2002). Axiomas concursales aceptados. Themis, 45, 7-24.

Barona Zuluaga, B. (2015). Principios de la OECD. Genealogía, descripción y explicación. En M. Puga de la Rocha (Ed.), Gobierno corporativo. Separata sobre artículos de interés (pp. 1-12).

Benavides, J. (2015). Historia del gobierno corporativo en el mundo. Definición y objetivos del gobierno corporativo. En M. Puga de la Rocha (Ed.), Gobierno corporativo. Separata sobre artículos de interés (pp. 1-10). 
Comisión de las Naciones Unidas para el Derecho Mercantil Internacional (CNUDMI). (2006). Guía legislativa sobre el régimen de insolvencia. Nueva York, NJ: ONU.

Corporación Andina de Fomento. (2010). Gobierno corporativo. Lo que todo empresario debe saber. Recuperado de https://www.caf.com/ media/1390757/gobierno-corporativo-lo-que-todo-empresariodebe-saber.pdf

Del Águila, P. (2003). Apuntes sobre el dilema del prisionero. ¿Puede la teoría de juegos explicarnos acerca del sentido del derecho concursal? Advocatus, 8, 438-450.

Del Águila, P. (2005). Plan de reestructuración: aprobación, ejecución e incumplimiento. Derecho y Sociedad, 25, 307-320.

Díaz Ortega, E. (2013). Actualización de los principios de BGC para las sociedades peruanas. Lima: Superintendencia de Mercado de Valores.

Díaz Ortega, E. (2015). Beneficios del buen gobierno corporativo [presentación de diapositivas]. Lima: Universidad ESAN.

Espina, A. (1999). Crisis de empresas y sistema concursal. Madrid: Consejo Económico y Social.

Ezcurra Rivero, H. (2005). Sociedades insolventes. ¿Hasta dónde llegan las facultades del Estado para supervisar las decisiones de la Junta? En Estudios de derecho societario. Libro homenaje a Enrique Elías Laroza (pp. 251-296). Trujillo: Normas Legales.

Fondo Nacional de Financiamiento de la Actividad Empresarial (Fonafe). (2006). Código marco de BGC de empresas del Estado. Lima: El Peruano.

Giménez, I. (2003). El gobierno corporativo, el control de las empresas y la defensa de los derechos de los accionistas minoritarios. Revista Valenciana de Economía y Hacienda, 9, 123-148.

González, M. (2014). Código de BGC para las sociedades peruanas: contenido y alcance. Lima: Asociación de Empresas Promotoras del Mercado de Capitales (Procapitales).

Ley 27809, Ley General del Sistema Concursal. (8 de agosto del 2002). Lima, Perú. Recuperado del sitio de internet del Congreso de la República: http://www2.congreso.gob.pe/sicr/cendocbib/con4_ uibd.nsf/B 7D2BCF5E597A9C005257E2700545259/\$ FILE/2_LEY_27809_08_08_2002.pdf 
Morales Acosta, A. (2007). Entrevista: Panorama del gobierno corporativo en el Perú. Revista Peruana de Derecho de la Empresa, 64, 379-387.

OCDE. (2004). Principios de gobierno corporativo de la OCDE. Recuperado de https://www.oecd.org/daf/ca/corporategovernanceprinciples /37191543.pdf

Payet Puccio, J. A. (2003). Empresa, gobierno corporativo y derecho de las sociedades: reflexiones sobre la protección de las minorías. Themis, 46, 77-103.

Resolución 0707-2006/TDC-INDECOPI. (2006). Recuperado del sitio de internet de Indecopi: https://www.indecopi.gob.pe/documents /20182/177659/ResolucionN0707-2006-TDC.pdf/1b75b6bb-50c44881-9108-0d94a4900c74

Tonón, A. (1992). El derecho concursal. Buenos Aires: Ediciones de Palma. 
